\title{
TEACHING HIGH-SCHOOL STUDENTS NANOSCIENCE AND NANOTECHNOLOGY
}

Dimitris Stavrou, Emily Michailidi, Giannis Sgouros and Kyriaki Dimitriadi

Department of Primary Education, University of Crete, Greece

\begin{abstract}
Science education research has recognized the potential of NanoScience and nanoTechnology (NST) due to its contribution to scientific literacy of future generations. Scholars have identified nine "Big Ideas" as important enough to teach in order to understand NST issues. Based on these "Big Ideas" a teaching learning sequence for lower secondary students has been developed focused on: Size and Scale, Tools and Instrumentation, Size-Dependent Properties and ScienceTechnology-Society. The teaching sequence was implemented in a class of 15 students of a lower secondary school ( $8^{\text {th }}$ grade; aged $\left.14-15\right)$. Seven meetings took place; each one lasting about ninety minutes. The course was structured as follows: 1. Introduction. 2. How small is a nanometer? 3. How can we "see" the nanoworld? 4. Size-dependent properties: Change of the surface area to volume ratio. 5. Explaining the behavior of different textiles (ranged from hydrophilic to hydrophobic) when absorbing water drops. 6. Explaining color changes in gold nanoparticles. 7. Risk assessment of nanotechnology. Data have been collected by questionnaires, interviews, students' worksheets and field notes. The results seem to be encouraging for the teaching of NST issues even in lower levels of education.
\end{abstract}

\section{Introduction}

The rapid development and growing societal importance of NanoScience and Nanotechnology (NST) have evoked educational concerns throughout the world. In the past two decades a growing body of science education research has been carried out concerning NST issues (Hingant \& Albe 2010, Jones et al. 2013). Recognizing the important role of NST in science and society the US National Science Foundation (NSF) funded a series of workshops in order to work out basic teaching ideas of the nanoscience field. Nine "big ideas" have been identified as important enough to teach in order to understand NST issues: Size and Scale, Structure of Matter, Forces and Interactions, Quantum Effects, Size-Dependent Properties, Self-Assembly, Tools and Instrumentation, Models and Simulations, Science, Technology and Society (Stevens, Sutherland \& Krajcik 2009).

A number of studies related to these "Big Ideas" gives insights in students' understanding about NST issues. For example studies showed that proportional reasoning ability is essential for students' understanding about size and scale as well as the surface area to volume relationships (Jones et al. 2007, Taylor \& Jones 2009). Furthermore, Swarat et al. (2011) in a series of studies, aimed at exploring students' conceptions about size and scale in the context of undergraduate nanoscience and engineering courses, identified four major categories: fragmented, linear, proportional, and logarithmic. Blonder and Sakhnini (2012) implemented a module on size and scales and the surface area to volume ratio to $9^{\text {th }}$ grade students using a wide spectrum of instructional methods. This study indicated that the use 
of different instructional methods enhance students' understanding and increase their interest in nanotechnology.

As the nanoscale is not accessible to our everyday experience the role of scientific tools in the understanding of size and scale is highlighted (e.g. Blonder, 2010, Hingant \& Albe, 2010). Jones et al. (2003) found that students' understanding about microscale, virus morphology, and dimensionality was improved as a result of using the Atomic Force Microscope (AFM) with a haptic interface. The results of this study suggested that the use of technology as a tool for learning about morphology of very small objects may be beneficial. The influence of adding different types of haptic feedback (e.g. active touch and kinesthetic feedback) combined with computer visualizations on students' experiences was also explored (Jones et al., 2006). The researchers indicated that the haptic feedback not only made the instruction more engaging, but may also have influenced the way in which the students constructed their knowledge. Ambrogi et al. (2008) in a course for upper secondary students could promote both students' scientific knowledge and social skills (teamwork, communication and problem solving) using information and communication technology.

Despite the potential impact of NST applications in everyday life, the risks and ethical issues connected with NST applications in society is a crucial factor for citizens' attitudes toward NST. Moreover, students' risk perceptions are important for their participation in future social dialogue concerning NST and society. Simonneaux et al. (2013) observed in students' argumentation of risks about nanotechnology two contrasting tendencies: a) a positivist view that involved an individualistic use of nanotechnology and science and b) a critical and humanistic vision of the use of nanotechnology and science.

Taking into account the aforementioned findings we developed and evaluated a teaching learning sequence for lower secondary students. The aim was to record students' capabilities and difficulties in learning NST issues in real classroom settings.

\section{The Research Framework}

The research framework of the work is the "Model of Educational Reconstruction" (Duit et al. 2012). The model has been developed as a theoretical framework for studies investigating whether it is worthwhile and possible to teach particular science concepts, principles and views of the nature of science. The major aim of the model is to bring science content structure and educational concerns into a balance when developing teaching and learning sequences. The model consists of three closely interrelated components : (1) Clarification and analysis of science content, including hermeneutical-analytical research on subject matter clarification and analysis of the educational significance of a particular science content. (2) Research on teaching and learning, comprising investigations of students' perspectives and their development towards the scientific view as well as studies on teachers' views and beliefs of the science concepts, students' learning and their role in initiating and supporting learning processes. (3) Design and evaluation of teaching and learning environments, comprising the design of instructional materials, learning activities, and teaching and learning sequences. 
The process of Educational Reconstruction is recursive in nature i.e. a cyclical process of theoretical reflection, conceptual analysis, small scale curriculum development, and classroom research on the interaction of teaching and learning processes.

In our study the recursive research procedure started with a clarification of the science content structure followed by an analysis on science education literature on teaching nanoscience and nanotechnology. Taking into account the science education literature a further clarification of the scientific content took place. The results of the science content clarification and the analysis on science education literature were used to develop a teaching learning sequence. Students' capabilities and difficulties were investigated. Accordingly, science content analyses, investigations into students' perspectives and the design of learning environments are closely linked (Figure 1).

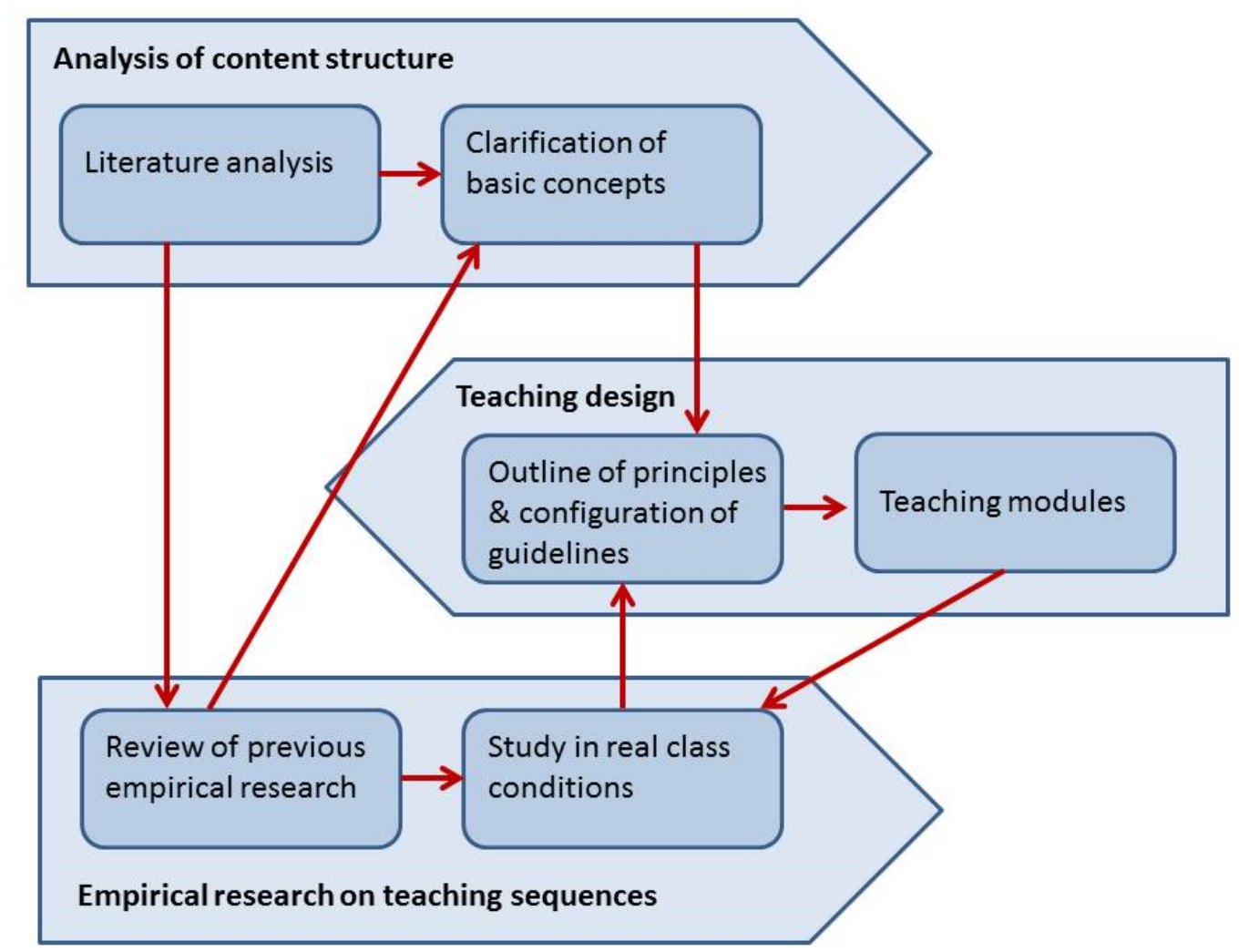

Figure1. The process of Educational Reconstruction in the present study

\section{The Teaching Learning Sequence}

Based on the research procedure described above we developed the following teaching learning sequence:

1st session: Introduction The aim of the first session was to raise students' interest about Nanoscience and Nanotechnology presenting various nanoscience applications (selfcleaning materials, nano- solar cells etc).

$2^{\text {nd }}$ session: Size and Scale The aim of the second session was students to realize the scale of nano and the fact that the tools we can use are proportional to the scale we work. 
Students had to put in order (from the large to the small) pictures with various objects of size from $1 \mathrm{~m}$ to $10^{-9} \mathrm{~m}$. Another task that students had to deal with was to cut a $1-$ meter - paper strip to 10 pieces, and each piece to 10 other pieces and so on. They were also asked to construct building blogs wearing and without wearing kitchen gloves in order to realize that we need tools of similar size to be effective.

$3^{\text {rd }}$ session: How can we "see" the nanoworld? The aim of the third session was students to deal with the problem "how can we see the nanoworld?" and to realize that "indirect" techniques are used. At the beginning we used the "black box" analogy (Figure 2, see also Kao et al. 2006, Turner et al. 2006). Objects of different height and properties (e.g. plastic cup, metal tin) were placed in a cardboard box. On the lid of the box we opened a number of holes. Students were given various tools (straws, pencils, markers with magnetic edges etc.) and had to identify and illustrate graphically the inner of the box.

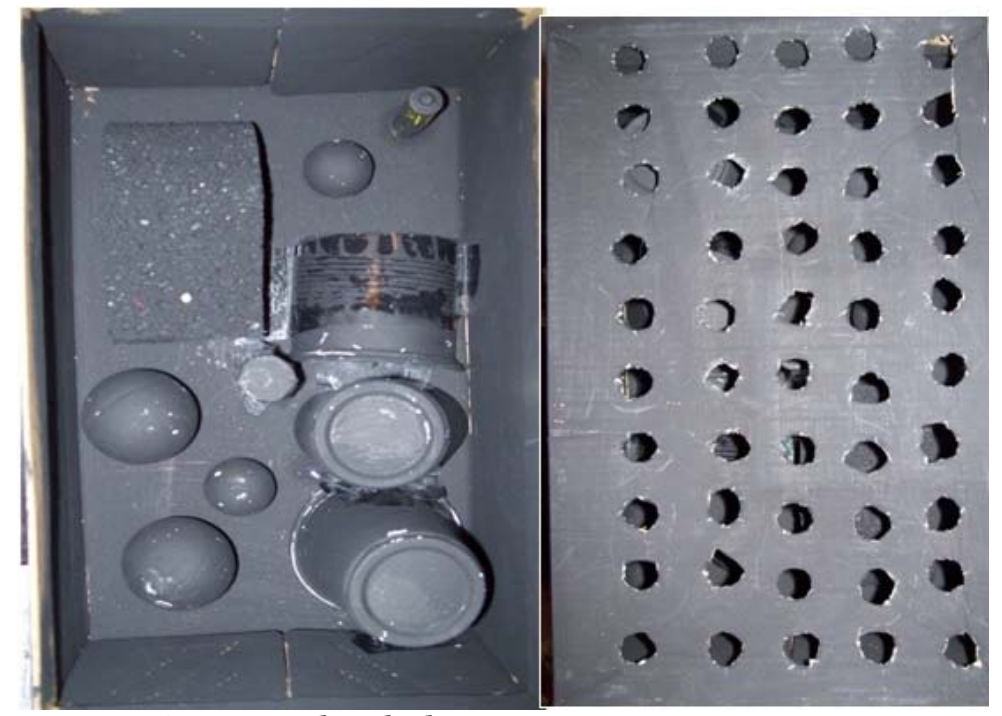

Figure 2. The Black Box

Afterwards a model of the Atomic Force Microscope (AFM) was used, which was constructed using a magnet adjusted on a small piece of a CD and a laser pointer (see Planinšič and Kovač 2008, Blonder 2010). A surface with metal caps covered by a paper was used as the sample surface (Figure 3). Students had to mark in a paper adjusted on the wall the reflected laser beam as the device scanned the surface. The result was a graph as shown in Figure 4. Based on this graph students had to find out the location of the caps. 


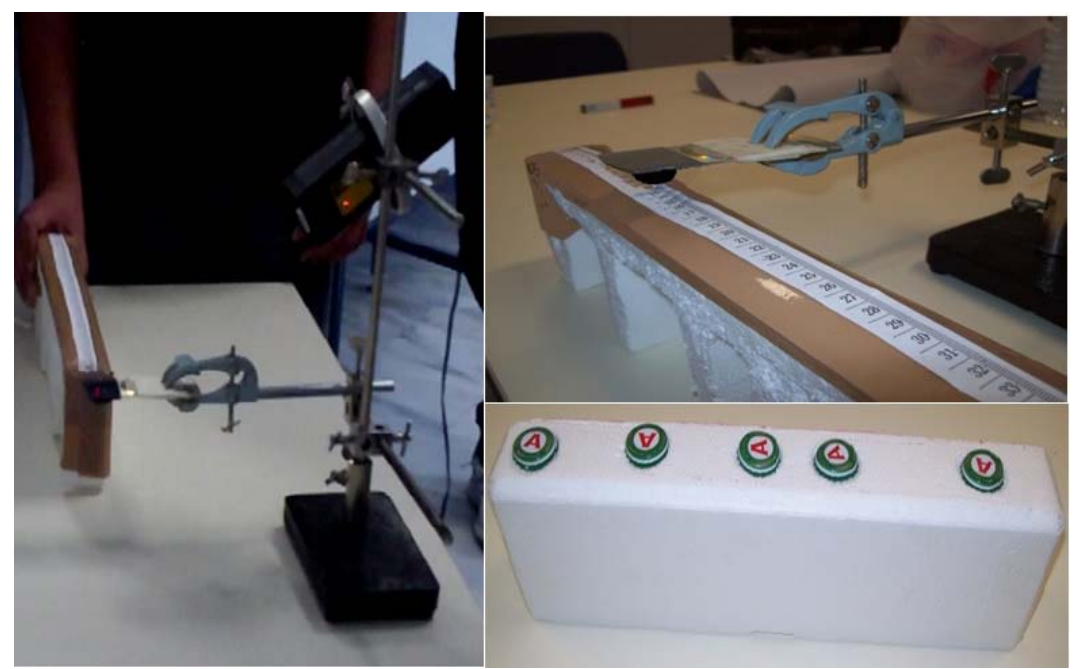

Figure 3. The AFM model used in the present study

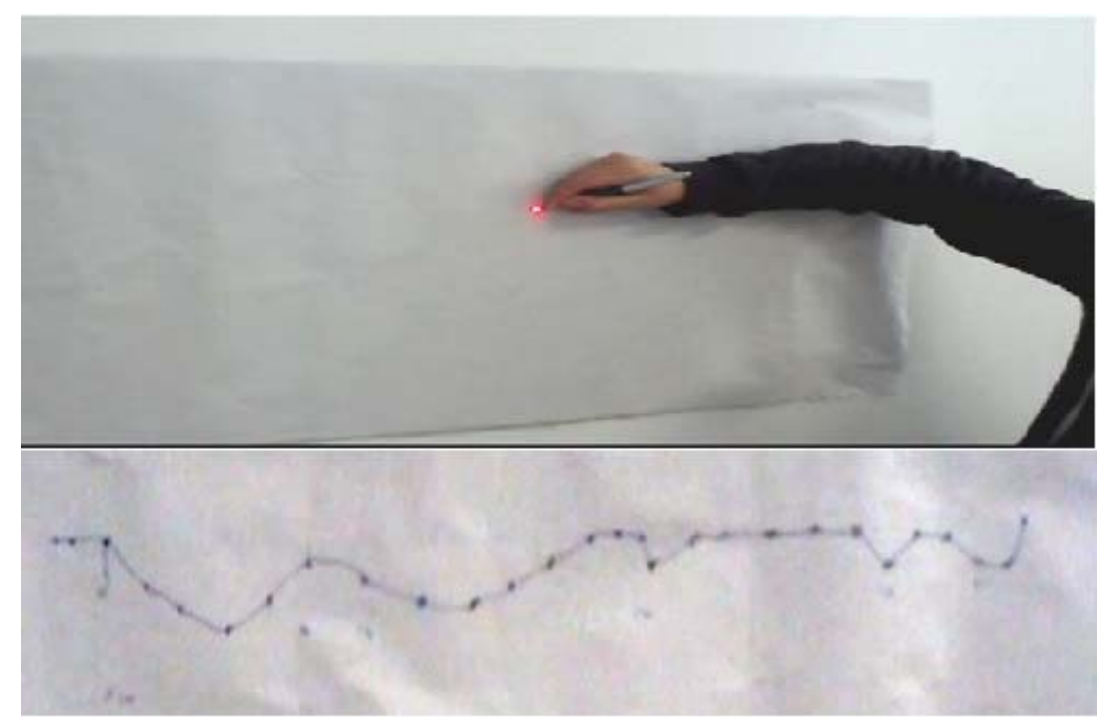

Figure 4. The resulting graph of the scanning over the sample surface

$4^{\text {th }}$ session: Size-dependent properties: Change of the surface area to volume ratio The aim of the fourth session was students to realize that the surface-to-volume ratio increases as the size of an object becomes smaller. Consequently, properties of materials dramatically change. As examples we used the behaviour of a steel nail, steel wire and steel wool after trying to burn them (Figure 5) and the behaviour of a piece of potato and of a similar potato cut into small pieces after reacting with hydrogen peroxide $\left(\mathrm{H}_{2} \mathrm{O}_{2}\right)$ (Figure 6). To support students' explanations a cube cut successively into 8 cubes and then in 27 cubes was provided (Figure 7). 


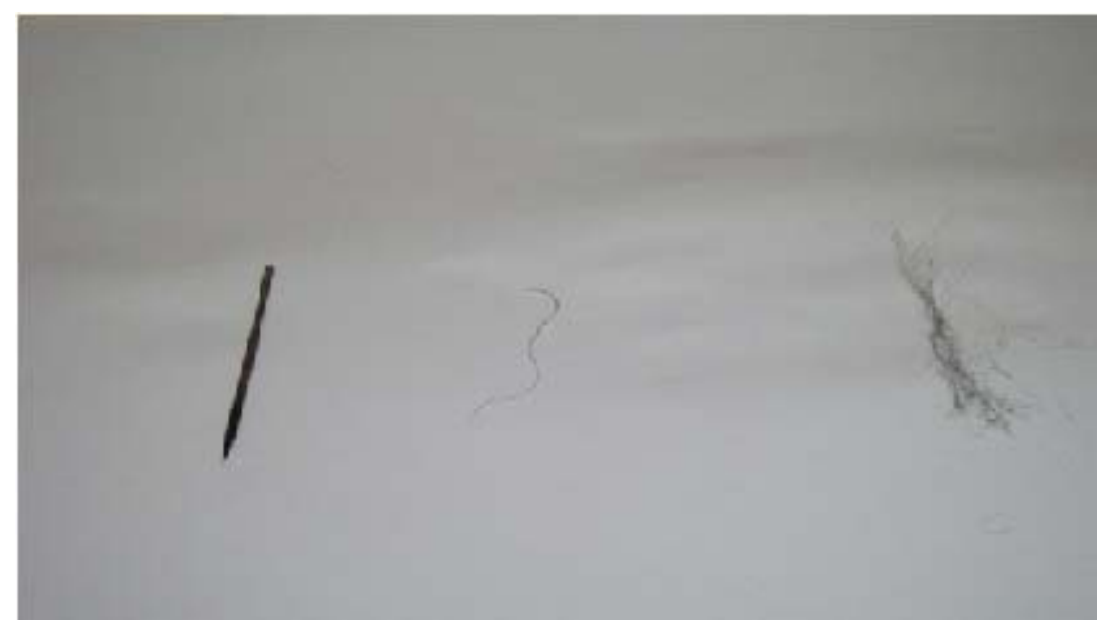

Figure 5. Steel nail (left), steel wire (middle) and steel wool (right)

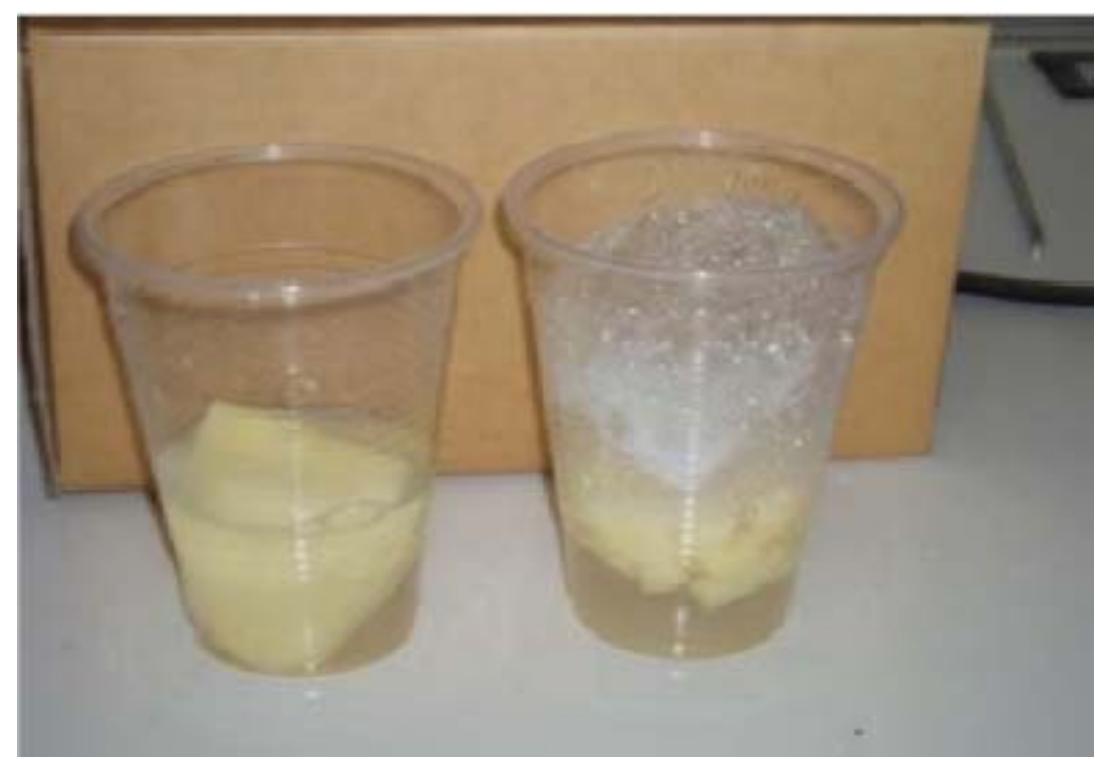

Figure 6. The behaviour of a piece of potato (left) and of a similar potato cut into small pieces (right) after reacting with hydrogen peroxide $\left(\mathrm{H}_{2} \mathrm{O}_{2}\right)$

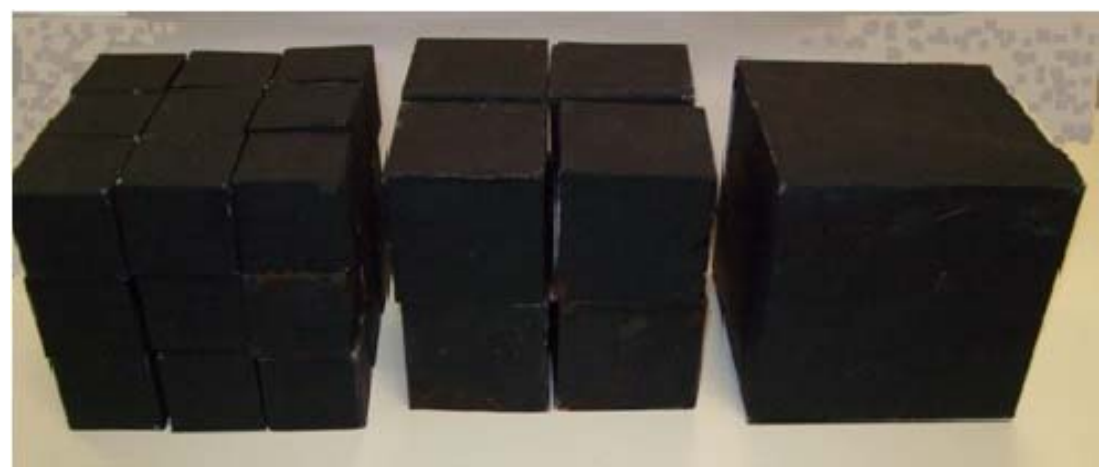

Figure 7. One cube (right) is cut into eight (middle) and twenty seven cubes (left)

$5^{\text {th }}$ session: Size-dependent properties: Explaining the behaviour of different textiles (ranged from hydrophilic to hydrophobic) when absorbing water drops. The aim of the fifth session was to explain the behavior of different textiles (ranged from hydrophilic to hydrophobic) when they are going to be cleaned after getting dirty (Figure 8). For the explanation of their behaviour the examples discussed in the $4^{\text {th }}$ session were used. Furthermore the analogy in Figure 9 illustrating the behaviour of hydrophilic, semihydrophilic and hydrophobic textiles was provided. 


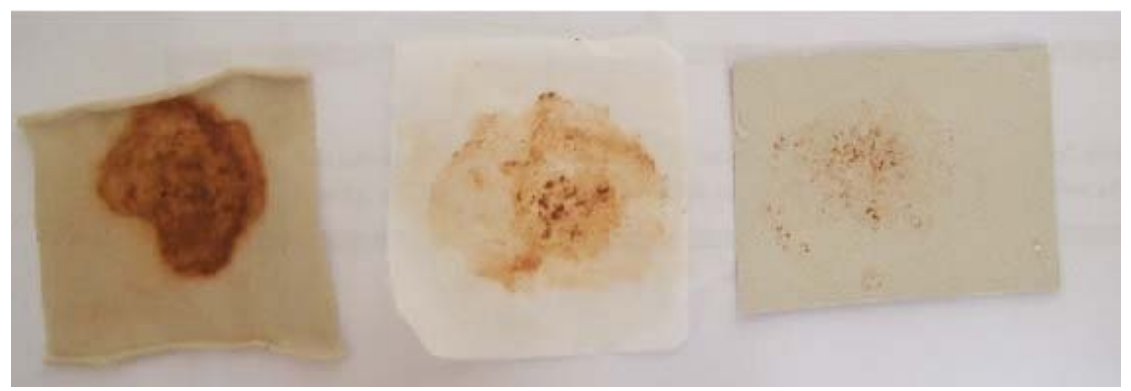

Figure 8. Three textiles with different absorption capacity of water

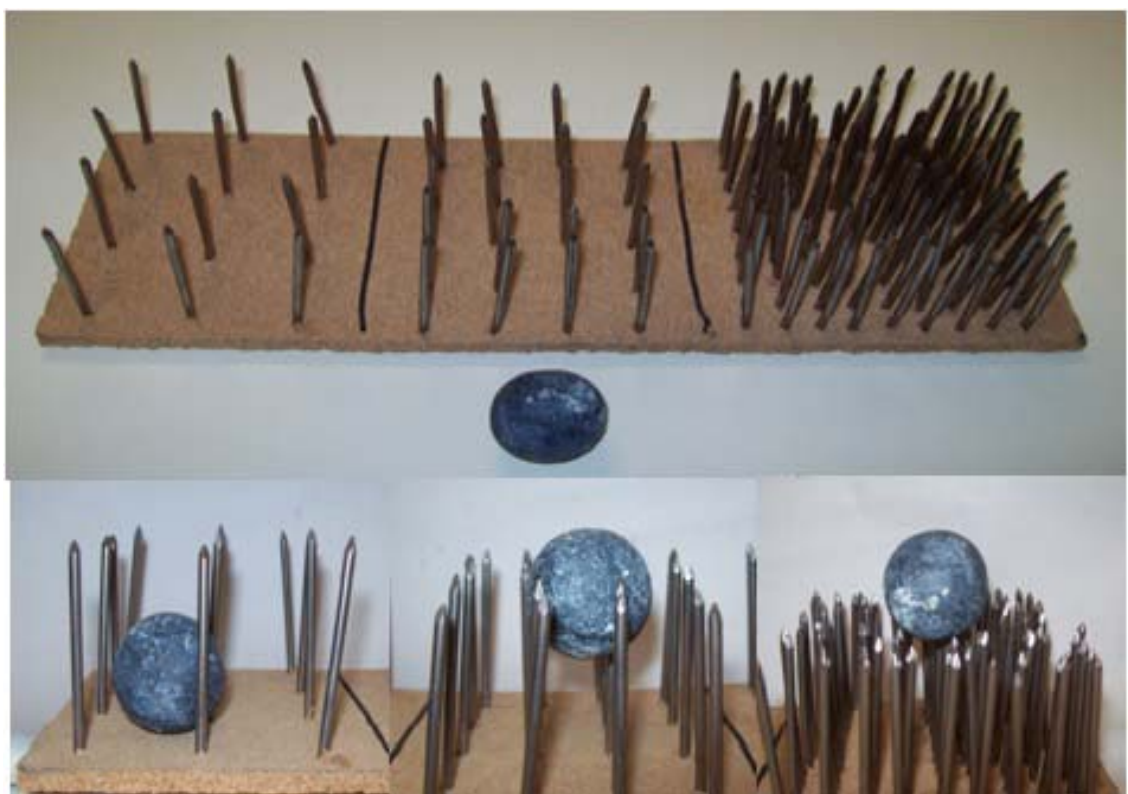

Figure 9. The water absorption analogy about the behaviour of hydrophilic (left), semihydrophilic (middle) and hydrophobic (right) textiles

\section{$6^{\text {th }}$ session: Size-dependent properties: Explaining color changes in gold} nanoparticles The aim of the sixth session was to explain the color changes in nanoscale gold colloids (Figure 10). Students had to realize that the different colors of the gold colloids are due to the change of their size in the nanoscale. Based on the $4^{\text {th }}$ and $5^{\text {th }}$ sessions the different properties are explained in terms of the change of the surface-to-volume ratio.

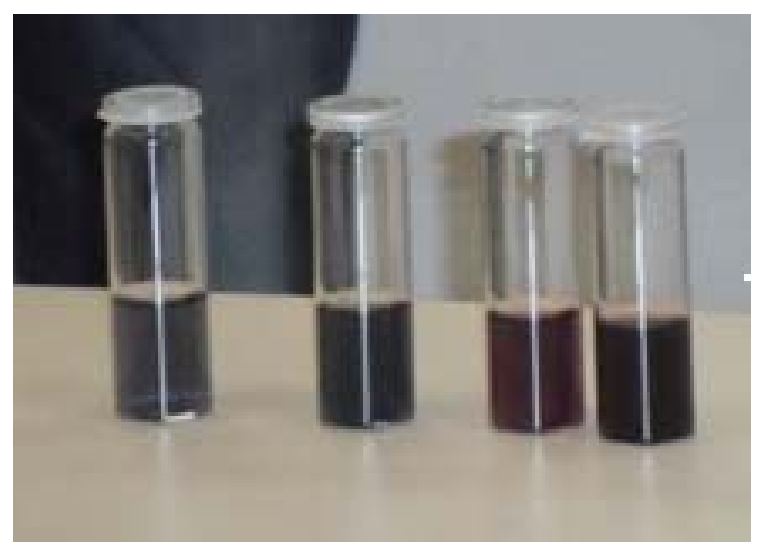

Figure 10. Nanoscale gold colloids 
$7^{\text {th }}$ session: Risk assessment of nanotechnology The aim of the seventh session was to raise students' awareness about the possible risks of NST. A discussion took place on possible risks and benefits of NST applications focusing on the fact that nanotechnology is an emergent science, so the effects may not be apparent for some time and the research on possible risks is at the beginning.

\subsection{Data Collection}

The teaching learning sequence was applied to a lower secondary class. Fifteen $8^{\text {th }}$ grade students (aged 14-15) took part in the investigation. Each session lasted about 90 minutes. To collect the data we used: i) a pre and post open-ended questionnaire to investigate students' conceptions about size and scale, how we can "see" nanoparticles, and sizedependent properties, ii) students' worksheets filled out during the meetings, iii) field notes and iv) semi-structured individual interviews after the implementation to investigate in depth students perspective.

Due to the exploratory nature of the study, the aim is not to test hypotheses but to develop preliminary hypotheses. Accordingly, we used methods of qualitative research for the data analysis (Cohen, Manion, \& Morrison 2007).

\section{Results}

In the following, the major findings of the study are presented.

\subsection{Size and scale}

Students showed no difficulty in putting in order familiar, everyday objects, but there was a great confusion at the level of non-visible to the naked eye objects. Only molecules and atoms, which were known as the building blocks of the material world, were put to the correct order by a large percentage of students. In contrast, it was not an easy task for the students to put in order the objects in the area between atoms and the first visible object (human hair). In general, students had difficulties to realize the absolute and relative size of invisible objects.

\subsection{Tools and Instrumentation}

Most students originally stated that it is possible to cut a piece of paper several nanometers long with an ordinary pair of scissors. By carrying out the activities of the $2^{\text {nd }}$ session they noticed that for handling objects they need tools that their dimensions are proportional to the size of the objects they want to handle. Specifically, they realize that the observation of nanoscale objects requires special tools, which work utilizing a different type of interaction than the optical microscope (that uses light), because the particles are smaller than the wavelength of light. The activity with the AFM model significantly helped children to understand the process of "seeing the nanoworld". 


\subsection{Size dependent properties}

Students did not have any idea about size-dependent properties. They believe that objects have fixed properties. This causes some difficulties at the beginning, but gradually students accepted that a change of properties is possible due to the object's size. Furthermore students struggled to understand the change of the surface area to volume ratio because of their limited proportional reasoning ability. So, an emphasis was laid on the increase of the surface when objects become smaller, which facilitated students' understanding. As regards the optical properties of gold, they needed time to clarify that color changes occur exclusively in the nanoscale.

\subsection{Science, Technology and Society: Risk assessment}

During the discussion on nano-ethics, there was noted a strong students' tendency to adopt extreme positions trying either to defend nanotechnology or to reject it. After some negotiation, however, the majority accepted that a more critical attitude towards innovative applications is necessary. There was a consensus that basic subject matter knowledge is essential so that one can decide on its usefulness or the potential risk. In overall students could acquire knowledge about the contribution of nanoscience to improve our standard of living, but also about the potential risks that may pose.

\section{Discussion and Conclusions}

The present study illustrates that the teaching-learning sequence developed appears to provide students of $8^{\text {th }}$ grade valuable insights on basic ideas of NST. The findings allow us to estimate that the whole process can enhance students' understanding on nanotechnology and their awareness of social and ethical issues related to science and technology. Our findings about students' difficulties towards the science point of view are in agreement with findings of other researchers (e.g. Swarat et al. 2011, Magana et al. 2012). Particularly, students had difficulty in understanding and comparing sizes at the micro-level. This can be attributed to the lack of everyday experience of these objects and the students' difficulty in understanding the absolute and relative size of invisible objects. Furthermore, the concept of the surface-to-volume ratio was quite difficult for children to elaborate due to their limited proportional reasoning ability. So, instead of focusing on the ratio, we put an emphasis on the increase of the surface when objects become smaller, which was more easily understood by the students. The main difficulty that students faced trying to explain the change of the optical properties of gold is connected to their idea that properties remain invariable at all scales. It is noteworthy, that this conception is still deeply rooted in student teachers (Stavrou \& Euler 2012).

Despite the difficulties students showed we can assert that the results are encouraging for teaching key features of Nanoscience and Nanotechnology even in lower secondary education. Furthermore the topic of NST was of particular interest to students. Although the teaching learning sequence was implemented in a typical lower secondary class, due to the explorative character of the study the findings have to be understood as preliminary 
hypotheses. They have to be tested to more school classes. At this time in the context of the Irresistible EU-project (http://www.irresistible-project.eu) activities described in this paper are included in a module developed in Greece. This module is now in the phase of implementation in five school classes of primary and secondary education. Next year it will be applied to other twenty five classes. We, therefore, expect more insights in students understanding about NST topics. 


\section{TEACHING HIGH-SCHOOL STUDENTS NANOSCIENCE AND NANOTECHNOLOGY}

\section{References}

Ambrogi, P., Caselli, M., Montalti, M. and Venturi, M., (2008). Make sense of nanochemistry and nanotechnology, Chemistry Education Research and Practice, 9, 5-10.

Blonder, R. \& Sakhnini, S. (2012). Teaching two basic nanotechnology concepts in secondary school by using a variety of teaching methods. Chemistry Education Research and Practice, 13, 500516.

Blonder, R. (2010). The Influence of a Teaching Model in Nanotechnology on Chemistry Teachers' Knowledge and Their Teaching Attitudes, J ournal of Nano Education, 2, 67-75.

Cohen, L., Manion, L., \& Morrison, K. (2007). Research Methods in Education (6 th $^{\text {th }}$ dition). LondonNew York: Routledge.

Duit, R., Gropengießer, H., Kattmann, U., Komorek, M., \& Parchmann, I. (2012). The Model of Educational Reconstruction - A framework for improving teaching and learning science. In D. Jorde \& J. Dillon (Eds.), The World Handbook of Science Education - Handbook of Research in Europe (pp. 13-37). Rotterdam, Taipei: Sense Publisher

Hingant, B. \& Albe, V. (2010). Nanosciences and nanotechnologies learning and teaching in secondary education: a review of literature. Studies in Science Education, 46, 121-152.

Jones, M.G., Andre, T., Superfine, R., \& Taylor, R. L. (2003). Learning at the nanoscale: The impact of students' use of remote microscopy on concepts of viruses, scale, and microscopy. J ournal of Research in Science Teaching, 40,3, 303-322.

Jones M.G., Blonder R. Gardner G.E., Albe V., Falvo M. \& Chevrier J. (2013). Nanotechnology and Nanoscale Science: Educational challenges. International J ournal of Science Education, 35, 1490-1512.

Jones, M. G., Minogue, J., Tretter, T. R., Negishi, A., \& Taylor, R. (2006). Haptic augmentation of science instruction: Does touch matter? Science Education, 90,1, 111-123

Jones, M.G., Taylor, A., Minogue, J., Broadwell, B., Wiebe, E., \& Carter, G. (2007). Understanding scale: Powers of ten. J ournal of Science Education and Technology,16, 191-202.

Kao, Y., Cina, A., Gimm,A. (2006). Inside the black box. The science teacher, 73, 9, Dec 06.

Magana, A., Brophy, S. \& Bryan L. (2012). An Integrated Knowledge Framework to Characterize and Scaffold Size and Scale. Cognition. International J ournal of Science Education, 34, 14, 21812203.

Planinšič, G. \& Kovač, J (2008). Nano goes to school: a teaching model of the atomic force microscope. Physics Education, 43, 1, 37-45.

Stavrou, D. \& Euler, M. (2012). Exploring Primary Student Teachers' Conceptions of Size Dependent Properties at the Nanoscale. CnS - La Chimica nella Scuola XXXIV - 3, 358-361 (Proceedings of the ICCE-ECRICE 2012 Conference, Rome, August 2012).

Stevens, S., Sutherland, L. \& Krajcik, J. (2009). The big ideas' of nanoscale science and engineering. Arlington, VA: National Science Teachers Association press.

Swarat S., Light G., Park E. J. \& Drane D. (2011), A typology of undergraduate students' conceptions of size and scale: Identifying and characterizing conceptual variation. J ournal of Research in Science Teaching, 48, 512-533.

Simonneaux, L., Panissal, N. \& Brossais, E. (2013). Students' Perception of Risk About Nanotechnology After an SAQ Teaching Strategy. International J ournal of Science Education, $35,14,2376-2406$

Taylor, A. \& Jones, G. (2009). Proportional Reasoning Ability and Concepts of Scale: Surface area to volume relationships in science. International J ournal of Science Education, 31, 9, 1231-1247

Turner, K., Campbell, J., Tevaarwerk, E., Chandrasekhar, V., Chang, R., Unterman, N., Grdinic, M. (2006). Seeing the unseen. The scanning probe microscope and nanoscale measurement. The science teacher, 73, 9, December 2006. 